\title{
Biodiesel Production from Unrefined Rice Bran Oil through Three-Stage Transesterification
}

\author{
V. R. Kattimani' ${ }^{1}$ B. M. Venkatesha ${ }^{2}$, S. Ananda ${ }^{3}$ \\ ${ }^{1}$ Department of Chemistry, Basaveshwar Engineering College, Bagalkot, India \\ ${ }^{2}$ Department of Chemistry, Yuvaraja's College, University of Mysore, Mysore, India \\ ${ }^{3}$ Department of Studies in Chemistry, University of Mysore, Mysore, India \\ Email: veeranna rk@yahoo.co.in
}

Received 11 February 2014; revised 11 March 2014; accepted 9 April 2014

Copyright (C) 2014 by authors and Scientific Research Publishing Inc.

This work is licensed under the Creative Commons Attribution International License (CC BY). http://creativecommons.org/licenses/by/4.0/

c) (i) Open Access

\begin{abstract}
Unrefined rice bran oil (UNRFRBO) with high free fatty acids (FFA) is used as a source for the production of unrefined rice bran oil methyl ester (UNRFRBOME). Three-stage transesterification process is successfully used. Initially, the FFA of UNRFRBO is reduced to $1 \%(0.8 \%)$ by using two stages esterification process with methanol in the presence of acid $\left(\mathrm{H}_{2} \mathrm{SO}_{4}\right)$ as a catalyst. Finally, biodiesel has produced by alkaline $(\mathrm{NaOH})$ catalyzed transesterification process which has designed according to the central composite design. $90 \%$ has obtained at the optimum values of $\mathrm{CH}_{3} \mathrm{OH}(20 \% \mathrm{v} / \mathrm{v}$ of oil), $\mathrm{NaOH}(1.0 \% \mathrm{w} / \mathrm{v}$ of oil), reaction time (60 minutes) and reaction temperature $\left(55^{\circ} \mathrm{C}\right.$ to $\left.60^{\circ} \mathrm{C}\right)$.
\end{abstract}

\section{Keywords}

Biodiesel, Ricebran Oil, Free Fatty Acid, Transesterification

\section{Introduction}

Due to clean emission profile, ease of use and other benefits biodiesel quickly become one of the fastest growing alternative fuels in the world.

The future of biodiesel lies in the world's ability to produce renewable feedstock such as vegetable and animal oils, to keep the cost of biodiesel competitive with petroleum.

The rice bran oil is extracted from the rice bran, which is a byproduct obtained during the grinding of paddy. Since rice is the staple food in a large part of south Asia, there is a huge potential to produce and utilize rice bran 
oil. India is the second largest producer of paddy. Hardly 50\% of the bran is utilized for producing rice bran oil and $19 \%$ of edible grade rice bran oil is consumed for cooking, hence Rice bran oil is commercially feasible for biodiesel production.

Rice bran oil is a byproduct obtained from outer layers of brown rice kernel during milling operation to produce polished rice. Rice bran has 16 wt\% to $32 \mathrm{wt} \%$ [1] oil (lipids) and nutraceutical compounds are depending on the rice variety and degree of milling.

Crude RBO is difficult to refine because of its high free fatty acid contents, dark color, and a large amount of un-saponifiable matter. FFA content as high as $4 \%$ to $8 \%$ has been found [1] in the oil that has obtained from bran immediately after milling of rice.

Few researchers [2]-[4] investigated biodiesel production from crude RBO by alkaline catalyzed transesterification process. However, possibility of soap formation increases with the use of this method as its FFA level found to be more than $1 \%$ and finally it affects the quality and quantity of biodiesel. Many researchers [5] [6] used acid catalyzed transesterification process for biodiesel production from RBO and conducted a series of experiments at 1:10 molar ratio of oil/methanol, $2 \mathrm{wt} \% \mathrm{H}_{2} \mathrm{SO}_{4}$, and reaction temperature of $60^{\circ} \mathrm{C}$ for a wide range of FFA. Researchers found that biodiesel yield decreased with an increase in FFA level. Considerable research has also been done on biodiesel production from RBO by using two-stage transesterification and lipase catalyzed transesterification process. Alcoholysis of crude RBO can be achieved under mild reaction conditions and in short reaction times in the presence of lipases. Lipase catalyzed transesterification allows easy recovery of glycerol with any purification method. In this work, an attempt has been made to use three-stage transesterification processes to convert UNRFRBO into UNRFRBOME.

The below figure represent the three-stage transesterification process for the unrefined ricebrane oil.

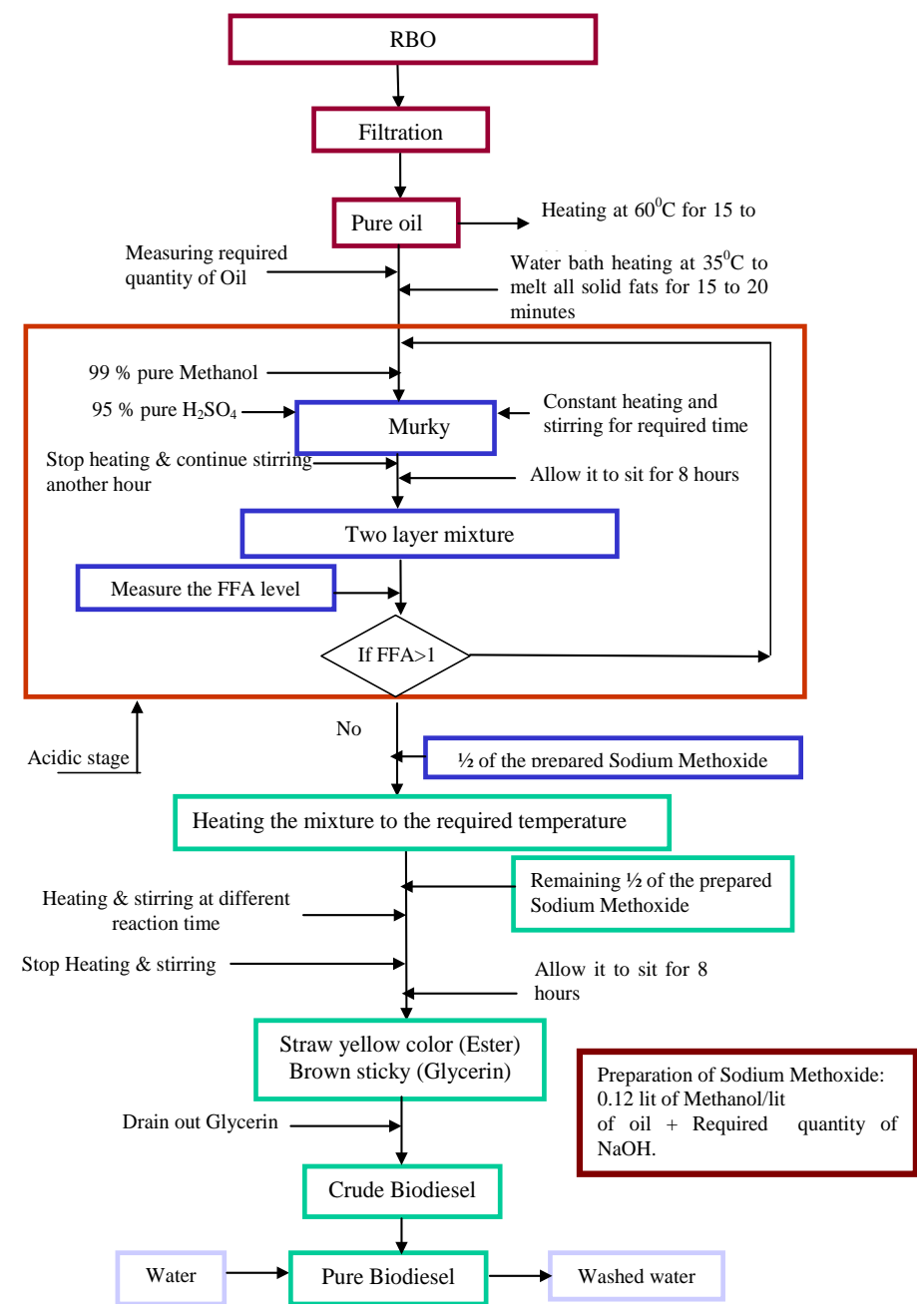




\section{Materials}

Required quantity of UNRFRBO is purchased from a rice mill near Tumkur, Karnataka State, India. All chemicals such as methanol (99.5\% purity), $\mathrm{H}_{2} \mathrm{SO}_{4}$ (99\% purity), $\mathrm{NaOH}$ pellets have purchased from VASA scientific company, Bangalore, Karnataka State, India. All chemicals were of analytical grade.

\subsection{Characterization of UNRFRBO}

Fatty acid composition of UNRFRBO.

Table 1 shows the fatty acid composition of UNRFRBO.

\subsection{Physical Properties of UNRFRBO}

Table 2 shows physical properties of UNRFRBO. UNRFRBO has a higher amount of FFA (8\%) which is above the accepted limit (i.e., 1\%) for alkaline catalyst transesterification process. Therefore, in this work pretreatment stages have used to convert FFA into esters by treating UNRFRBO with methanol in the presence of an acidic catalyst $\left(\mathrm{H}_{2} \mathrm{SO}_{4}, 0.5 \% \mathrm{v} / \mathrm{v}\right)$ to bring the FFA amount to less than $1 \%$. Finally, transesterification process is completed by using an alkaline catalyst.

\section{Stage 1 Acid Catalyzed Esterification Process}

In this stage, nine experiments have conducted by varying methanol quantity $(2.5 \%, 5 \%$, and $7.5 \% \mathrm{v} / \mathrm{v}$ of oil) and reaction time (45 min, $60 \mathrm{~min}$, and $75 \mathrm{~min}$ ). Experiments were conducted by keeping acid catalyst concentration $\left(\mathrm{H}_{2} \mathrm{SO}_{4}, 0.5 \% \mathrm{v} / \mathrm{v}\right)$ and reaction temperature $\left(55^{\circ} \mathrm{C}\right.$ to $\left.60^{\circ} \mathrm{C}\right)$ constant.

\subsection{Experimental Procedure}

UNRFRBO has taken into the reactor. Water bath temperature is maintained at $55^{\circ} \mathrm{C}$ to $60^{\circ} \mathrm{C}$. Required amount of $\mathrm{CH}_{3} \mathrm{OH}$ added to the concentrated $\mathrm{H}_{2} \mathrm{SO}_{4}(0.5 \% \mathrm{v} / \mathrm{v}$ of oil $)$. The mixture slowly added to the heated oil. Stirring at low RPM and heating $\left(55^{\circ} \mathrm{C}\right.$ to $\left.60^{\circ} \mathrm{C}\right)$ is continued for different reaction times. Similar methods were used for all nine experiments which were conducted according to the experimental matrix shown in Table 3 . On completion of reaction, the mixtures were allowed to fall into two layers. The excess methanol, $\mathrm{H}_{2} \mathrm{SO}_{4}$, and impurities moved to the top surface and were taken out. The acid value of the product separated at the bottom is measured.

Table 3 shows the FFA level for different combination of $\mathrm{CH}_{3} \mathrm{OH}$ and reaction time for UNRFRBO for Stage-1 acid catalyzed transesterification process.

\begin{tabular}{ccc}
\multicolumn{3}{l}{ Table 1. Fatty acid composition of UNRFRBO. } \\
\hline Sl. No & Components & UNRFRBO (\% by weight) \\
\hline 1 & Palmitic acid (16:0) & 20.12 \\
2 & Stearic acid (18:0) & 2.8 \\
3 & Oleic acid (18:1) & 40 \\
4 & Linoleic acid (18:2) & 30 \\
5 & Linolenic acid (18:3) & 2.5 \\
\hline
\end{tabular}

Table 2. Physical properties of UNRFRBO.

\begin{tabular}{cccc}
\hline Sl. No & Properties & Unit & RBO \\
\hline 1 & Viscosity at $40^{\circ} \mathrm{C}$ & $\mathrm{cSt}$ & 12.3 \\
2 & Density & $\mathrm{kg} / \mathrm{m}^{3}$ & 914 \\
3 & Flash point & ${ }^{\circ} \mathrm{C}$ & 260 \\
4 & Calorific value & $\mathrm{MJ} / \mathrm{kg}$ & 36.16 \\
5 & Pour point & ${ }^{\circ} \mathrm{C}$ & -5 \\
\hline
\end{tabular}


Table 3. Layout of experimental design and results for Stage-1 acid catalyzed transesterification process.

\begin{tabular}{ccccc}
\hline Experiment No & Samples & $\mathrm{CH}_{3} \mathrm{OH}(\% \mathrm{v} / \mathrm{v}$ of oil $)$ & Reaction time in minutes & FFA (\%) \\
\hline 1 & $\mathrm{~S}_{1}$ & 2.5 & 45 & 6.5 \\
2 & $\mathrm{~S}_{2}$ & 2.5 & 60 & 5 \\
3 & $\mathrm{~S}_{3}$ & 2.5 & 75 & 3.5 \\
4 & $\mathrm{~S}_{4}$ & 5 & 45 & 3.8 \\
5 & $\mathrm{~S}_{5}$ & 5 & 60 & 2.5 \\
6 & $\mathrm{~S}_{6}$ & 5 & 75 & 2 \\
7 & $\mathrm{~S}_{7}$ & 7.5 & 45 & 2.2 \\
$\mathbf{8}$ & $\mathbf{S}_{\mathbf{8}}$ & $\mathbf{7 . 5}$ & $\mathbf{6 0}$ & $\mathbf{1 . 8}$ \\
9 & $\mathrm{~S}_{9}$ & 7.5 & 75 & 2.2 \\
\hline
\end{tabular}

\subsection{Stage 2 Acid Catalyzed Esterification Process}

Sample $\left(\mathrm{S}_{8}\right)$ has selected as a source for this stage because it has minimal FFA level (1.8\%). Table shows the experimental conditions for Stage 2 acid catalyzed transesterification process. In this stage also, nine experiments have conducted by varying methanol quantity (2\%, $4 \%$, and $6 \% \mathrm{v} / \mathrm{v}$ of oil) and reaction time (45 min, 60 $\mathrm{min}$, and $75 \mathrm{~min}$ ) according to the experimental matrix shown in Table 4. Experiments have conducted by keeping acid catalyst concentration $\left(\mathrm{H}_{2} \mathrm{SO}_{4}, 0.5 \% \mathrm{v} / \mathrm{v}\right)$ and reaction temperature $\left(55^{\circ} \mathrm{C}\right.$ to $\left.60^{\circ} \mathrm{C}\right)$ constant. Experiments were conducted by using the procedure that has used for stage 1 acid catalyzed esterification process. The acid value of the product at the bottom is measured. The product having minimum FFA level is chosen as a source for the third stage.

\subsection{Stage 3 Alkaline Catalyzed Transesterification Process}

Sample $\left(\mathrm{S}_{88}\right)$ has selected as a source for alkaline catalyzed transesterification process as its FFA amount less than $1 \%$ (i.e., $0.6 \%)$.

\subsection{Experimental Procedure}

Sample $\left(\mathrm{S}_{88}\right)$ (Table 4) has taken into the reactor. Water bath is maintained at $55^{\circ} \mathrm{C}$ to $60^{\circ} \mathrm{C}$ temperature. Sodium methoxide solution is prepared by dissolving required amount of $\mathrm{NaOH}$ in desired amount of $\mathrm{CH}_{3} \mathrm{OH}$. Half of the prepared sodium methoxide solution slowly added to the heated oil. Stirring and heating continued for 10 to 15 minutes. Then, remaining half of the prepared sodium methoxide solution slowly added to the heated mixture.

Stirring at low RPM and heating $\left(55^{\circ} \mathrm{C}\right.$ to $\left.60^{\circ} \mathrm{C}\right)$ is continued for another 45 minutes to 50 minutes (i.e., total reaction time of 60 minutes). Similar method has used for all 12 experiments which have conducted according to the experimental matrix shown in Table 5. On completion of reaction, the mixtures allowed to fall into two layers with the UNRFRBO on the top and glycerol on the bottom. The raw UNRFRBOME collected, and water washed twice to bring the $\mathrm{pH}$ of UNRFRBOME to 7.

\section{Results and Discussion}

\subsection{Stage 1 Acid Catalyzed Esterification Process}

Figure 1 shows that the effect of methanol quantity and reaction time on FFA level of UNRFRBO. Figure shows that the reaction progressed rapidly in the initial stage and became slower in the later phase. It also shows that the FFA level steadily decreased with an increase in the quantity of methanol at the same period of reaction time. Sample $\mathrm{S}_{8}$ has minimum FFA (1.8\%) at the optimized methanol quantity of $7.5 \% \mathrm{v} / \mathrm{v}$ of oil and reaction time (60 minutes). Sample $\left(\mathrm{S}_{8}\right)$ has used for Stage 2 acid catalyzed esterification process. 
Table 4. Layout of experimental design and results for Stage 2 acid catalyzed transesterification process.

\begin{tabular}{cccccc}
\hline Experiment No & Type of feedstock & Samples & $\mathrm{CH}_{3} \mathrm{OH}(\% \mathrm{v} / \mathrm{v}$ of oil) & Reaction time in minutes & FFA (\%) \\
\hline 1 & $\mathrm{~S}_{81}$ & 2 & 45 & 1.6 \\
2 & $\mathrm{~S}_{82}$ & 2 & 60 & 1.4 \\
3 & $\mathrm{~S}_{83}$ & 2 & 75 & 1.5 \\
4 & $\mathrm{~S}_{84}$ & 4 & 45 & 1.3 \\
5 & Sample & $\mathrm{S}_{85}$ & 4 & 60 & 0.8 \\
6 & $\mathrm{~S}_{8}$ & $\mathrm{~S}_{86}$ & 4 & 75 & 1.1 \\
7 & & $\mathrm{~S}_{87}$ & 6 & 45 & 1.2 \\
8 & & $\mathrm{~S}_{88}$ & $\mathbf{6}$ & $\mathbf{6 0}$ & $\mathbf{0 . 6}$ \\
9 & & $\mathrm{~S}_{89}$ & 6 & 75 & 1 \\
\hline
\end{tabular}

Table 5. Experimental matrix and experimental results.

\begin{tabular}{cccc}
\hline Exp. No & $\mathrm{CH}_{3} \mathrm{OH}(\% \mathrm{v} / \mathrm{v}$ of oil) & $\mathrm{NaOH}(\% \mathrm{w} / \mathrm{v}$ of oil) & Biodiesel yield (\% v/v of oil) \\
\hline 1 & 15 & 0.5 & 80.2 \\
2 & 25 & 0.5 & 82.1 \\
3 & 15 & 1.5 & 70.5 \\
4 & 25 & 1.5 & 65.5 \\
5 & 20 & 1.0 & $\mathbf{8 5 . 5}$ \\
6 & 20 & 1.0 & 85.0 \\
7 & 20 & 1.0 & 85.2 \\
8 & 20 & 1.0 & 85.2 \\
9 & 20 & 1.84 & 60.3 \\
10 & 28.4 & 1.0 & 63.3 \\
11 & 11.6 & 1.0 & 60.4 \\
12 & 20 & 0.16 & 78.5 \\
\hline
\end{tabular}

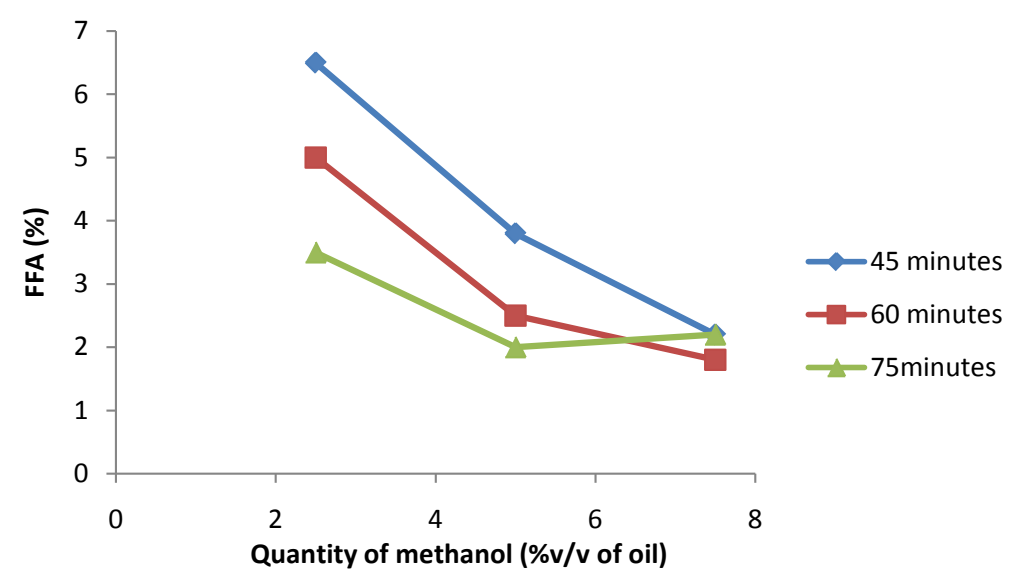

Figure 1. Influence of quantity of methanol and reaction time on FFA level of UNRFRBO.

\subsection{Stage 2 Acid Catalyzed Esterification Process}

Figure 2 shows the effect of the molar ratio of methanol to oil and reaction time on FFA level of sample $\mathrm{S}_{8}$. It 


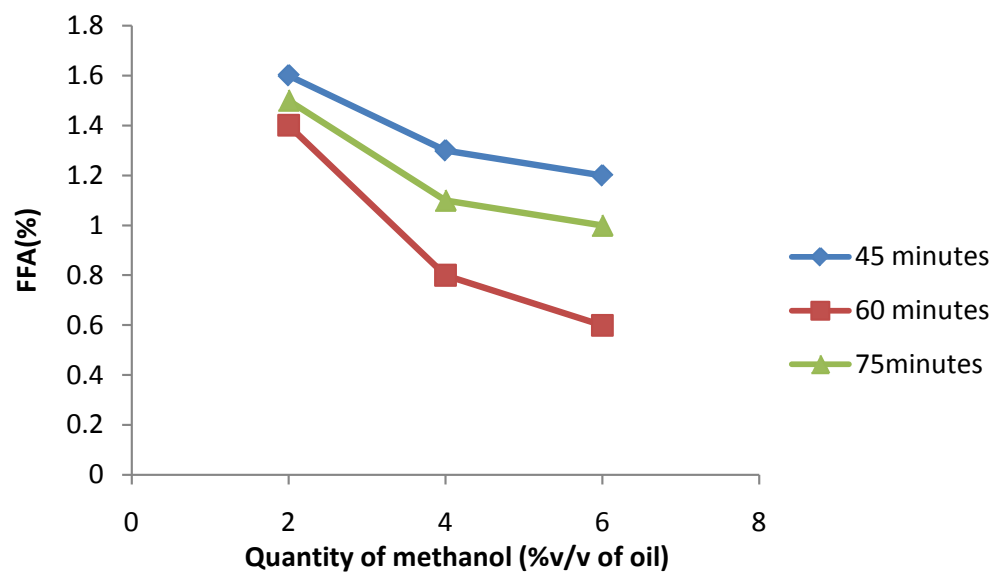

Figure 2. Influence of quantity of methanol and reaction time on FFA level of sample $\mathrm{S}_{8}$.

can be seen from the Figure that the reaction time showed the same trend as in case of the first stage. Sample $\mathrm{S}_{88}$ has minimum FFA (0.6\%) at the optimized methanol quantity $6 \% \mathrm{v} / \mathrm{v}$ of oil and reaction time (60 minutes). Sample $\left(\mathrm{S}_{88}\right)$ has selected for Stage 3 (alkaline catalyzed) esterification process.

\subsection{Stage 3 Alkaline Catalyzed Transesterification Process}

Alkaline catalyzed transesterification reaction is conducted using the pretreated $\mathrm{S}_{88}$ with FFA level of $0.6 \%$. In order to get the optimal conditions for maximum UNRFRBOME yield, experiments have been conducted according to CCD experimental matrix (Table 5).

\section{References}

[1] Ju, Y.-H. and Vali, S.R. (2005) Rice Bran Oil as a Potential Resource for Biodiesel: A Review. Journal of Scientific and Industrial Research, 64, 866-882.

[2] Freedman, B., Pryde, E.H. and Mounts, T.L. (1984) Variables Affecting the Yields of Fatty Esters from Transesterified Vegetable Oil. Journal of American oil Chemist Society, 61, 1638-1643.

[3] Kusy, P.G. (1982) Transesterification of Vegetable Oils for Fuels. Proceedings of International Conference on Plants and Vegetable Oils as Fuel, Fargo North Dakota, 2-4 August 1982, 127-137.

[4] Knothe, G., Dunn, R.O. and Bagby, M.O. (1997) The Use of Vegetable Oils and Their Derivatives as Alternative Diesel Fuels. In: Saha, B.C. and Woodward, J., Eds., Fuels and Chemicals from Biomass, American Society, Washington DC, 172-2008. http://dx.doi.org/10.1021/bk-1997-0666.ch010

[5] Lin, L., Ying, D., Chaitep, S. and Vittayapadung, S. (2009) Biodiesel Production from Crude Rice Bran Oil and Properties as Fuel. Applied Energy, 86, 681-688. http://dx.doi.org/10.1016/j.apenergy.2008.06.002

[6] Goff, M.J., Bauer, N.S., Lopes, S., Sutterlin, W.R. and Suppes, G.J. (2004) Acid-Catalyzed Alcoholysis of Soybean Oil. Journal of the American Oil Chemists' Society, 81, 415-420. 
Scientific Research Publishing (SCIRP) is one of the largest Open Access journal publishers. It is currently publishing more than 200 open access, online, peer-reviewed journals covering a wide range of academic disciplines. SCIRP serves the worldwide academic communities and contributes to the progress and application of science with its publication.

Other selected journals from SCIRP are listed as below. Submit your manuscript to us via either submit@scirp.org or Online Submission Portal.
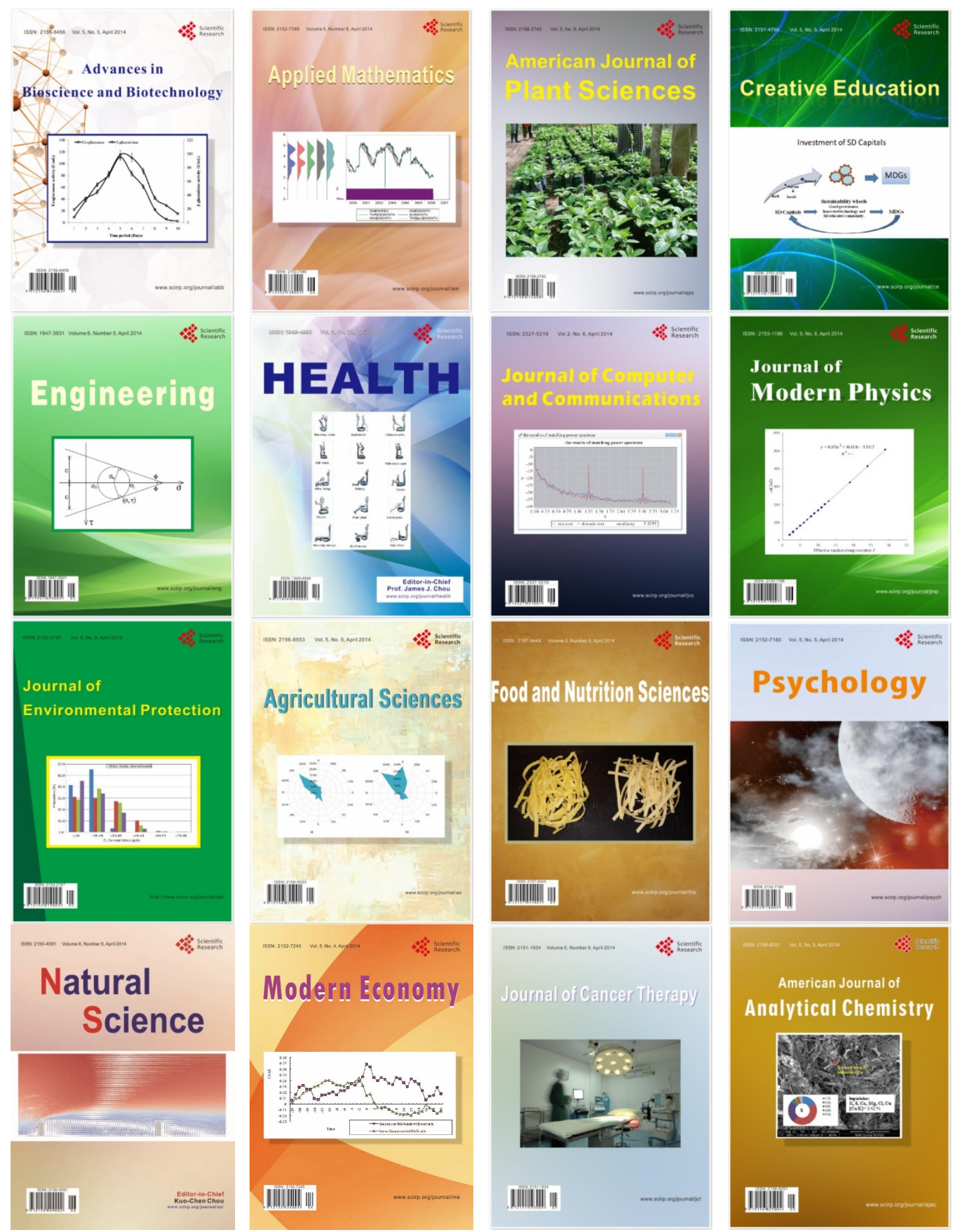